\title{
EU28 region's water security and the effect of bioenergy industry sustainability
}

\begin{abstract}
Water is an essential component of agriculture-food production. As the biomass and biofuel are known excellent sources of renewable and sustainable energy, cultivating process consumes significant quantities of water. Without sufficient, good-quality and easily accessible water, the European agriculture-food production could thus be under threat. This research analyses the impact of the water supply on the bioenergy production in the 28 European Union countries, for the 19902018 period within the pathway of the European Union 2030 agenda for sustainable development. The findings using the generalised least squares (GLS) technique show that bioenergy production and population density appear to decrease water supply. Precisely, the magnitude of the effects is - 0.224 and - 0.136 for developing countries and developed countries in the EU, respectively. This indicates that a serious reduction of water security is more likely to happen in developed countries than in developing countries as a result of the increase in bioenergy consumption. In the meantime, fossil fuel, income generation activities and institutional quality have already positively affected water supply. Thus, these findings implied that water scarcity is becoming one of the main obstacles for bioenergy expansion and growth. The results were also further verified by the random effect and pooled oriented least squares method. This study recommends that the Member of the European Union States should continue to increase bioenergy production in the energy mix efforts without any strenuous water security issues. Notwithstanding, there are several situations where a developing bioenergy industry is unlikely to be constrained by water shortage, and with the drive of bioenergy demand, the efforts might unlock new opportunities to adapt to water-related challenges and to improve water usage efficiencies. The authorities should illustrate organised water security and sustainable bioenergy policy by way of developing alternative strategies in reducing fossil fuel power and related $\mathrm{CO} 2$ emissions, accordingly to the unique characteristics of both developed and developing countries in the EU.
\end{abstract}

Keyword: Bioenergy growth; EU countries; Sustainable development; Water supply 